\title{
Effects of fluctuating daily surface fluxes on the time-mean oceanic circulation
}

\author{
Balan Sarojini Beena $\cdot$ Jin-Song von Storch
}

Received: 21 September 2007/Accepted: 6 April 2009/Published online: 23 April 2009

(C) Springer-Verlag 2009

\begin{abstract}
The effect of fluctuating daily surface fluxes on the time-mean oceanic circulation is studied using an empirical flux model. The model produces fluctuating fluxes resulting from atmospheric variability and includes oceanic feedbacks on the fluxes. Numerical experiments were carried out by driving an ocean general circulation model with three different versions of the empirical model. It is found that fluctuating daily fluxes lead to an increase in the meridional overturning circulation (MOC) of the Atlantic of about $1 \mathrm{~Sv}$ and a decrease in the Antarctic circumpolar current (ACC) of about $32 \mathrm{~Sv}$. The changes are approximately $7 \%$ of the MOC and $16 \%$ of the ACC obtained without fluctuating daily fluxes. The fluctuating fluxes change the intensity and the depth of vertical mixing. This, in turn, changes the density field and thus the circulation. Fluctuating buoyancy fluxes change the vertical mixing in a non-linear way: they tend to increase the convective mixing in mostly stable regions and to decrease the convective mixing in mostly unstable regions. The ACC changes are related to the enhanced mixing in the subtropical and the mid-latitude Southern Ocean and reduced mixing in the high-latitude Southern Ocean. The enhanced mixing is related to an increase in the frequency and the depth of convective events. As these events bring more dense water downward, the mixing changes lead to a reduction in meridional gradient of the depth-integrated density in the Southern Ocean and hence the strength of the ACC. The MOC changes are related to more subtle density changes. It is found that the vertical mixing in a latitudinal
\end{abstract}

B. S. Beena $\cdot$ J.-S. von Storch $(\bowtie)$

Max-Planck Institute for Meteorology, Bundestrasse 53,

20146 Hamburg, Germany

e-mail: jin-song.von.storch@zmaw.de strip in the northern North Atlantic is more strongly enhanced due to fluctuating fluxes than the mixing in a latitudinal strip in the South Atlantic. This leads to an increase in the density difference between the two strips, which can be responsible for the increase in the Atlantic MOC.

Keywords Fluctuating daily fluxes - Vertical mixing · Meridional overturning circulation - Antarctic circumpolar current $\cdot$ Air-sea interaction

\section{Introduction}

The issue of what determines the strength of the global meridional overturning circulation (MOC) has drawn the attention of many researchers. The prevailing view is that the circulation is driven partly by the diapycnal mixing of heat that lightens water masses in the deep ocean and causes them to rise uniformly in low latitudes (Munk and Wunsch 1998), and partly by wind-driven upwelling induced by the strong westerly circumpolar winds in the Southern Ocean (Webb and Suginohara 2001; Toggweiler and Samuels 1995). Both the diapycnal mixing and the wind-driven upwelling focus on the mechanisms that allow deep dense water masses to return to the surface. The surface buoyancy forcing, though not considered as a driver of the MOC capable for providing energy supply, is necessary for setting up the flow by controlling the rate and site of the deep water formation (Kuhlbrodt et al. 2007).

The major factors which control the MOC in the above picture are the diapycnal mixing, the upwelling due to wind forcing and the rate and the site of deep water formation set up by the surface buoyancy forcing. All these factors are 
directly or indirectly related to the air-sea fluxes. So far, the analyses have mainly focused on the effects of climatological mean components of the wind forcing in providing the energy required for diapycnal mixing or in inducing wind-driven upwelling (Munk and Wunsch 1998; Webb and Suginohara 2001; Toggweiler and Samuels 1995). This paper aims at a detailed picture that can isolate the effect of fluctuating day-to-day fluxes from that of the mean fluxes.

Generally, the role of air-sea fluxes in determining the stratification and the circulation of the oceans has been known for long time. Such a role has been investigated within theoretical frameworks (Walin 1982; Tziperman 1986) and with respect to change in convection (Rahmstorf 1995; Kuhlbrodt and Monahan 2003; Swingedouw et al. 2007). Walin (1982) studied the relation between sea-surface heat flux and thermal circulation in the ocean. Tziperman (1986) derived a relation between the interior stratification and the air-sea heat fluxes and used this relation to study the buoyancy driven circulation. The role of surface flux anomalies in triggering convection was studied by Rahmstorf (1995). Using a simple box model, Kuhlbrodt and Monahan (2003) showed that the variability of surface fluxes is important for the open ocean convection and deep water formation in the Labrador Sea. Swingedouw et al. (2007) found a linear relationship between density changes in the convection sites and the strength of the Atlantic MOC.

Even though the previous studies support the important role of day-to-day anomalies of air-sea fluxes, it is generally difficult to obtain a quantitative estimation of the impact of all fluctuating fluxes on the MOC in the framework of GCMs. For instance, it is obvious that an evaporation anomaly can lead to the formation of water denser than $1,028 \mathrm{~kg} \mathrm{~m}^{-3}$, while a precipitation anomaly can lead to the formation of water lighter than $1,028 \mathrm{~kg} \mathrm{~m}^{-3}$. With these anomalies, water mass production denser than $1,028 \mathrm{~kg} \mathrm{~m}^{-3}$ can occur. Without these anomalies, but with the same time-mean buoyancy forcing, the water mass production denser than $1,028 \mathrm{~kg} \mathrm{~m}^{-3}$ would have been zero. However, what is less clear is the net effect of all buoyancy anomalies on the oceanic circulation.

The effect of fluctuating fluxes can be strongly non-linear. For example, consider buoyancy anomalies occuring in a mostly stable region. In this case, positive anomalies (e.g. due to a precipitation event or a downward positive heat flux anomaly) may not significantly affect the statistics of convective events (since the water column is already stable), whereas negative anomalies (e.g. due to an evaporation event or a negative heat flux anomaly) could significantly increase convective events, resulting in nonlinear responses to fluctuating fluxes.
Given the potential and complexity of daily air-sea fluxes in changing the water mass production and from that the interior stratification and circulation, the effect of daily fluxes is investigated using a coupled system, specially developed for this purpose. The system consists of an ocean GCM and an empirical global flux model which describes the day-to-day flux variations in a realistic manner. The advantage of this system is that it allows a separation of effects of fluctuating air-sea fluxes from that of the climatological mean fluxes. Such a separation is difficult within a fully coupled atmosphere and ocean GCM. Numerical experiments were carried out using the hybrid coupled model. As will be shown, the fluctuating daily fluxes affect not only the Atlantic MOC, but also the Antarctic circumpolar current (ACC). The models and the numerical experiments are described in Sects. 2 and 3. The results of the experiments are presented in Sect. 4. Discussion and conclusions are given in the final section.

\section{Model description}

The empirical flux model and the OGCM used in this study are briefly introduced below. A more detailed description can be found in von Storch et al. (2005) and Marsland et al. (2003).

\subsection{The empirical model of daily air-sea fluxes: EMAD}

The flux model, referred to as empirical model of atmospheric dynamics (EMAD), is designed to generate air-sea flux anomalies relative to given climatological mean fluxes. Based on the assumption that deviations from a given mean state of the coupled system are small, the dynamics of the flux anomalies and the response of these fluxes to anomalous sea surface condition are considered to be linear and described by

$\mathbf{x}_{t+1}^{\prime}=\mathcal{A} \mathbf{x}_{t}^{\prime}+\mathcal{C} \mathbf{n}_{t+1}+\mathcal{B} \mathbf{y}_{t}^{\prime}$.

$\mathbf{x}^{\prime}$ comprises anomalies of all fluxes required to drive the OGCM. These are the net heat flux, the zonal and meridional momentum flux, the freshwater flux, the short-wave radiation which penetrates into the sea water, and the conductive and residual heat flux required to describe the sea ice formation and depletion. $\mathbf{y}^{\prime}$ represents anomalies of oceanic variables at the sea surface, such as the sea surface temperature (SST), the sea ice cover and the sea ice thickness, that can affect the fluxes. $\mathbf{n}$ is a multivariate white noise with zero mean and unit variance. $\mathcal{A}$ describes the linear dynamics of the fluxes, $\mathcal{B}$ the linear response of fluxes to the ocean surface condition, and $\mathcal{C}$ the covariance 
structure of the residual that is not depicted by $\mathcal{A}$ and $\mathcal{B}$. The time step of Eq. 1 is 1 day.

$\mathcal{A}, \mathcal{B}$ and $\mathcal{C}$ are matrices obtained by fitting Eq. 1 onto the daily output of a 200 -year control integration performed with the fully coupled ECHO-G atmosphere ocean general circulation model (AOGCM) (Legutke and Voss 1999; Raible et al. 2001). The fitting is done first for $\mathcal{A}$ and $\mathcal{B}$ in EOF-spaces represented by the leading EOFs of fluxes and then for $\mathcal{C}$ in the physical space. We use 100 EOFs for each flux and 100 EOFs for SST in the water module (further explained below) and 50 EOFs for each of the same variables in the ice module. The physical space has the Gaussian grid of T30 resolution.

The EMAD model consists of a water module and an ice module for the separate treatment of the fluxes over permanently open water and sea surface where ice can be formed. The formulation of the two modules is necessary to deal with the additional fluxes which are required to drive the sea-ice model. Different from the water module, the state vector $\mathbf{x}^{\prime}$ in the ice module contains the conductive and residual heat and distinguishes the fluxes of net heat, fresh water and momentum over ice and water. Depending on the sea ice fraction within a grid cell, either the fluxes over ice or the fluxes over water or both will be used to drive the ocean.

Without the last term, the model Eq. 1 mimics the linear dynamics of flux anomalies driven by the atmospheric variability. The last term with $\mathcal{B}$ describes the oceanic feedbacks on the fluxes. Since $\mathcal{B}$ is derived from a coupled model integration which is essentially statistically stationary, the interaction described by $\mathcal{B} \mathbf{y}^{\prime}$ acts to keep the ocean in the given mean state. This means that, if the sea surface condition is moved away from the given sea surface state, there would be non-zero anomalies of sea surface variables and from that a non-zero $\mathbf{y}^{\prime}$, which generates anomalous fluxes $\mathcal{B} \mathbf{y}^{\prime}$ that drive the sea surface back to the given state.

The just described feedback mechanism involves essentially the interaction between the heat flux and the SST anomalies. It functions in a way as if the heat flux is described by a restoring condition. However, in contrast to the traditional restoring formulation which uses a constant restoration time, $\mathcal{B}$ implies a dependence of the restoration time on spatial scales. By formulating in EOFspace, $\mathcal{B}$ captures the restoring time scales for modes with different spatial scales in the ECHO-G integration. In particular, large-scale SST anomalies are allowed to exist over a longer time period, while small-scale SST anomalies will be damped out quickly. The need for such a scale-dependent restoration was first pointed out by Rahmstorf and Willebrand (1995). The present formulation can be considered as an empirical approach that captures the scale-dependent feedback of SST on heat flux in the ECHO-G integration. Due to the scale dependence, the $\mathcal{B} \mathbf{y}^{\prime}$-term does not act as a rigid restoring. One does not obtain exactly the same SST when using $\mathcal{B} \mathbf{y}^{\prime}$ to nudge SSTs to the same climatological mean SST (see Sect. 4.1).

By collecting all fluxes into vector $\mathbf{x}^{\prime}$ and all relevant sea surface variables in vector $\mathbf{y}^{\prime}$, the model Eq. 1 ensures that the fluxes and the oceanic variables are physically coherent. When coupling EMAD to an OGCM, the fluxes of heat, fresh water and momentum will not respond independently to a given anomalous state of the sea surface.

The noise term acts to excite the EOF-modes described by the deterministic part of EMAD (i.e. by $\mathcal{A}$ - and $\mathcal{B}$ terms). The matrix $\mathcal{C}$ ensures that the distributions of the total variances of the fluxes match those obtained from the coupled ECHO-G model.

Despite the extremely simple form, the model Eq. 1 is able to describe various types of air-sea interactions. If $\mathcal{A} \mathbf{x}^{\prime}+\mathcal{C} \mathbf{n}$ dominates $\mathcal{B} \mathbf{y}^{\prime}$ for a certain flux, this flux would force the ocean by and large stochastically. This could be the case for wind stress anomalies over high-latitudes, where the influence of the SST on the wind stress is weak. If the $\mathcal{A}$-term and the $\mathcal{B}$-term have similar strength, the flux would be affected both by the stochastic forcing and by the oceanic feedback. If the $\mathcal{B}$-term dominates, the flux would be essentially determined by the oceanic conditions. The relative importance of the various types of air-sea interactions is given by the amplitudes of elements of $\mathcal{A}$ and $\mathcal{B}$. The result of different types of air-sea interactions can be identified by studying the lagged correlation functions between the flux and SST (Frankignoul et al. 1998; von Storch 2000).

The ability of EMAD in reproducing the second moments of fluxes found in the coupled ECHO-G is considered in von Storch et al. (2005). In particular, it was shown that EMAD produces variances of fluxes, whose strength and distribution are in general comparable to that found in ECHO-G. The various types of interactions, as can be identified using the lagged correlation functions between the SST and the fluxes (Frankignoul et al. 1998; von Storch 2000), are by and large reproduced when coupling EMAD to an OGCM. Finally, EMAD is able to act realistically to anomalous sea surface condition, such as those related to an ENSO event or to a Polynya.

To give the reader an idea of how the EMAD-fluxes look like, Fig. 1 shows anomalies of wind stress (arrows) and heat flux (colour shading), obtained by forcing EMAD with the anomalous sea surface conditions derived from the coupled ECHAM5/MPI-OM AOGCM (Jungclaus et al. 2005). Also shown in Fig. 1 is a snapshot of the anomalies of the same fluxes from the NCEP reanalysis for an 
Fig. 1 Daily snapshots of wind stress and heat flux anomalies from a EMAD model and $\mathbf{b}$ NCEP/NCAR reanalysis. The units are in Pascal and $\mathrm{W} \mathrm{m}^{-2}$, respectively

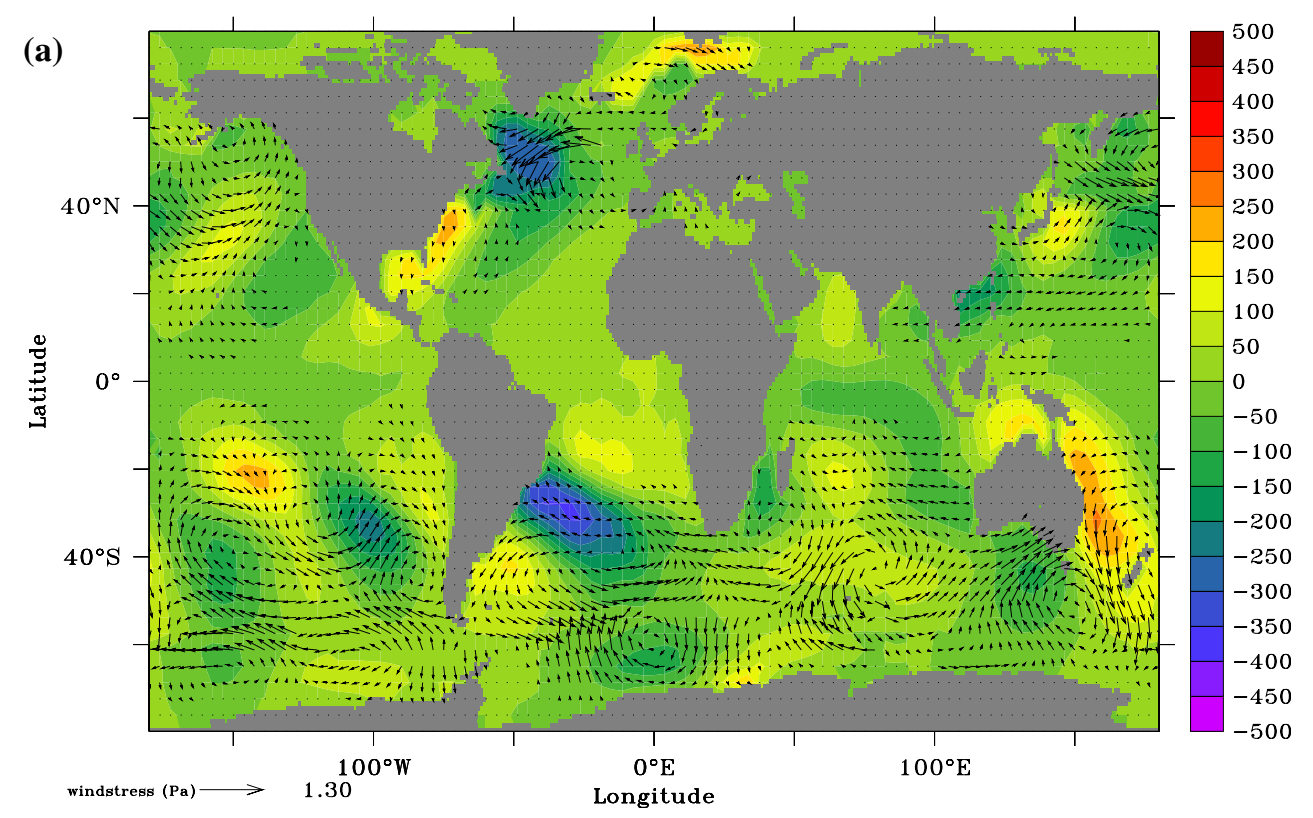

Heat Flux Anomaly $\left(\mathrm{w} / \mathrm{m}^{2}\right)$, EMAD

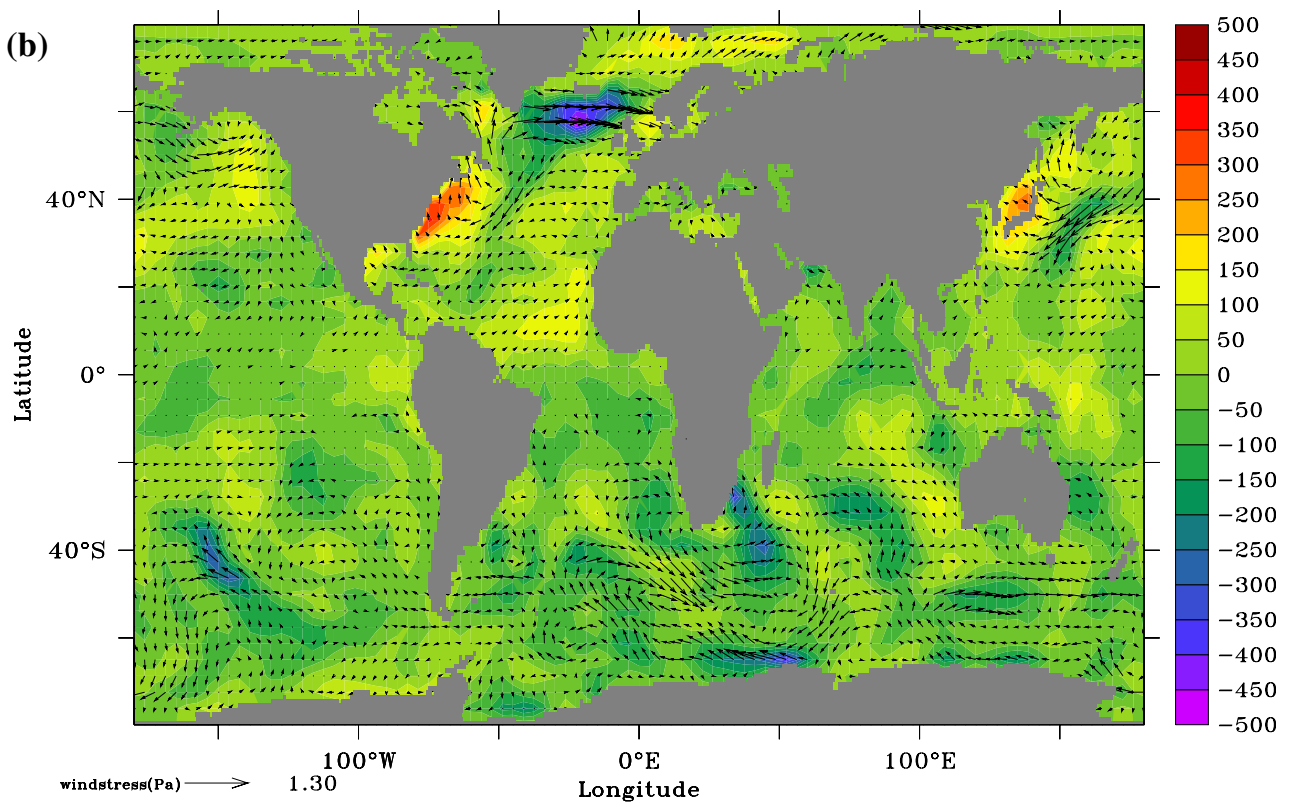

Heat Flux Anomaly $\left(\mathrm{W} / \mathrm{m}^{2}\right)$, NCEP arbitrary day. Similar to the fluxes of the reanalysis, the EMAD-fluxes have maxima at the mid- and high-latitudes. The amplitudes of EMAD-anomalies are slightly larger than those of the reanalysis. The structure of the EMADanomalies are somewhat smoother than that of the NCEPfluxes, reflecting the fact that EMAD describes the leading EOF-modes excited by white noise forcing. Figure 1 and the previous validation (von Storch et al. 2005) suggest that EMAD is capable of producing the basic features of the fluctuating day-to-day fluxes.
2.2 The ocean general circulation model: MPI-OM

The OGCM used in this study is the Max-Planck Institute Ocean Model (MPI-OM). It is a $z$-coordinate model based on primitive equations for a Boussinesq fluid on a rotating sphere. It is formulated on the horizontal Arakawa $\mathrm{C}$ grid with the north pole located at northern Greenland and south pole close to Weddell Sea. It has horizontal resolution varying from $20 \mathrm{~km}$ in the main sinking regions associated with the MOC to about $350 \mathrm{~km}$ in the tropics. For the 
present study, the model configuration with 40 vertical levels (Haak et al. 2003) is used. The model contains a free surface and a state-of-the-art sea ice model with viscousplastic rheology and snow. Overflow over the sills and off continental shelves are represented by a bottom boundary layer slope convection scheme.

Tracer diffusion is isoneutral and dianeutral and is described by the diffusion tensor $\mathcal{K}$ (Redi 1982), which is a function of the neutral density gradient and horizontal and vertical diffusion coefficients $K_{H}$ and $K_{V}$. The scheme is numerically implemented following Griffies (1998). The effect of horizontal tracer mixing by advection due to the unresolved mesoscale eddies is parameterized after Gent et al. (1995). The horizontal eddy viscosity is parameterized using a scale-dependent biharmonic formulation. The vertical eddy viscosity follows Pacanowski and Philander (1981). It utilizes an eddy coefficient which is represented in the same way as the vertical eddy diffusivity coefficient $K_{V}$ (see Eq. 2 below), except that the Richardson number dependent part is proportional to $(1+C R D R i)^{-2}$, rather than $\left(1+C_{R D} R i\right)^{-3}$ as given in Eq. 3. The vertical diffusion, as described by $K_{V}$ or in short $K$, plays an important role in the present study and is further described below.

$K$ is a function of convective mixing, Richardson number $(R i)$ dependent mixing, wind-induced mixing and background diffusivity (Marsland et al. 2003) and is given by

$K=\left\{\begin{array}{l}K_{\text {conv }} \quad \text { if statically unstable } \\ K_{R i}+K_{\text {wind }}+K_{\text {back }} \quad \text { if statically stable }\end{array}\right.$

with

$K_{R i}=D_{V O}\left(1+C_{R D} R i\right)^{-3}$,

where $R i$ is the Richardson number, $D_{V O}=2 \times 10^{-3}$ $\mathrm{m}^{2} \mathrm{~s}^{-1}$ and $C_{R D}=5$ are model constants. According to Eq. 3, the maximum value of $K_{R i}$ is $2 \times 10^{-3} \mathrm{~m}^{2} \mathrm{~s}^{-1}$. The diffusion related to convection $K_{\text {conv }}$ is set to $10^{-1} \mathrm{~m}^{2} \mathrm{~s}^{-1}$. Thus, static instability is removed by switching on an extremely strong mixing. In the surface layer, the windinduced mixing $K_{\text {wind }}$ over ice free regions is given by

$K_{\text {wind }}=W_{T} V_{10}^{3}$

where $V_{10}$ is the local $10 \mathrm{~m}$ wind speed and $W_{T}$ equals $5 \times 10^{-4} \mathrm{~m}^{-1} \mathrm{~s}^{2}$. Below the surface, $K_{\text {wind }}$ depends on the stability of the water column and decays exponentially with $e$-folding depth being $40 \mathrm{~m}$. The diffusion related to other unresolved processes, such as internal waves, is described by $K_{\text {back }}=10^{-5} \mathrm{~m}^{2} \mathrm{~s}^{-1}$. This set of parameters is used in the integration of MPI-OM coupled to the ECHAM5 AGCM (Jungclaus et al. 2005) that produces a realistic oceanic state.

The vertical diffusion coefficient $K$ can vary spatially and temporally, depending on the static stability and wind forcing. Since $K_{b a c k}$ is unchanged in the experiments performed and since $K_{\text {wind }}$ is confined to the first $40 \mathrm{~m}$ of the ocean (depending on the stability), the changes in $K$ below $40 \mathrm{~m}$ are related to the changes in $K_{R i}$ and/or $K_{c o n v}$. Fluctuating fluxes can change both $K_{R i}$ and $K_{c o n v}$.

Fluctuating fluxes can affect $K_{\text {conv }}$ by turning convection on and off in a non-linear way, depending on the background static stability. In the regions where the stratification is mostly stable and $K_{\text {conv }}$ is mostly turned off, a positive buoyancy forcing (induced, e.g. by additional precipitation events or additional heat flux anomalies) makes the ocean more stable and hence will leave $K_{\text {conv }}$ switched off. By contrast, a negative buoyancy forcing will reduce static stability, and hence $K_{c o n v}$ might be switched on more often. The net effect is an increase in the convective mixing. Examples of mostly stable oceans are the tropical and subtropical oceans. On the other hand, in regions where the stratification is mostly unstable and $K_{\text {conv }}$ is mostly switched on, a negative buoyancy forcing will not affect the convective mixing much, since the convective mixing is already switched on. A positive buoyancy anomaly on the contrary can increase the static stability, making $K_{\text {conv }}$ switched on less often. The net effect is a decrease in $K$. Examples of mostly unstable oceans are the Greenland Iceland Norwegian (GIN) Seas and the high-latitude Southern Ocean in the MPI-OM model.

The above described changes in convective events are not inconsistent with previous numerical experiments in which the convection at single grid points can be switched on and off by flux anomalies and be crucial for maintaining deep water formation (Rahmstorf 1995; Kuhlbrodt and Monahan 2003).

Fluctuating fluxes can also change the Ri-dependent mixing, since a fluctuating buoyancy flux can affect the stratification of the water column and a fluctuating wind stress forcing can alter the shear of the current. The change in the $R i$-dependent mixing is expected to be more pronounced in the tropics. In these regions, the static stability of the ocean is so high that static instability rarely occurs and, when it occurs, it will be confined to a shallow surface layer.

In the present study, the vertical diffusion coefficient $K$ is stored on monthly basis. Since the maximum value of $K_{R i}$ of $2 \times 10^{-3} \mathrm{~m}^{2} \mathrm{~s}^{-1}$ is much smaller than $K_{\text {conv }}=$ $10^{-1} \mathrm{~m}^{2} \mathrm{~s}^{-1}$, large changes in $K$ must be related to changes in the number of convective events occurring within a month. Generally, a large increase (decrease) in $K$ indicates an increase (a decrease) in the number of convective events, and from that an increase (a decrease) in the formation of dense water masses. In this sense, changes in $K$ can be used as a crude measure of changes in water mass formation due to convection. As shown by the mean 
convection depth in Fig. 10a, the true deep water formation, reaching about 1,000 $\mathrm{m}$ depth on average, occurs only in GIN Seas and off the Antarctic coast in the Atlantic sector in the version of the MPI-OM model used here.

\subsection{The coupled model: EMAD/MPI-OM}

To couple the EMAD with the MPI-OM, the EMAD fluxes, which are on the T30-Gaussian grid, are interpolated into the curvilinear grid of the MPI-OM model. The coupling takes place once a day.

When coupling EMAD to the MPI-OM model, one needs a set of fields of climatological mean fluxes and a set of fields of climatological mean sea surface conditions. Both sets were derived from the last 50 years of a 600 -year integration with the ECHAM5/MPI-OM coupled AOGCM (Jungclaus et al. 2005). The climatology contains the annual cycle on a daily basis. Given an oceanic state at time $t$, the anomalous sea surface condition $\mathbf{y}^{\prime}$ is derived by subtracting the actual oceanic state from the given climatological mean state. With this $\mathbf{y}^{\prime}$ and the anomalous flux forcing $\mathbf{x}^{\prime}$ at $t-1$, EMAD produces the anomalous flux forcing at $t$. Adding this to the climatological mean forcing gives the net flux forcing at time $t$ which is used to produce $\mathbf{y}^{\prime}$ at time $t+1$.

It should be noted that since EMAD is only an approximation of ECHAM5, and since the $\mathcal{B} \mathbf{y}^{\prime}$-term is not a rigid restoring, the climatological mean state produced by the MPI-OM model coupled to EMAD generally does not match the climatological mean state produced by the fully coupled ECHAM5/MPI-OM. As a consequence, the timemean of $\mathbf{y}^{\prime}$ is not zero. This non-zero time-mean of $\mathbf{y}^{\prime}$ can feed back to the fluxes and produce non-zero time-mean of $\mathbf{x}^{\prime}$, whereby complicating the interpretation of the experiments to be introduced in Sect. 3. We will return to this issue later.

Apart from the feedbacks described by $\mathcal{B}$, there is no relaxation of salinity or temperature in the ocean. The only procedure used to prevent the ocean drifting away from the given climatological mean state is to restore the sea ice cover and sea ice thickness to that found in the integration with the ECHAM5/MPI-OM. The restoring time constant is chosen as 39 days.

\section{Numerical experiments}

To study the effect of fluctuating daily fluxes, three experiments were carried out. In the experiment BH, MPI$\mathrm{OM}$ was driven by the climatological mean fluxes of heat, fresh water and momentum plus an additional heat flux anomaly, $H^{\prime}$, which was obtained from $\mathcal{B} \mathbf{y}^{\prime}$ with $\mathbf{y}^{\prime}$ representing SST anomalies. This particular form of $\mathcal{B} \mathbf{y}^{\prime}$ contains the SST feedbacks that prevent large climate drifts. This is shown by an additional experiment in which the MPI-OM model was driven by the fixed climatological fluxes only. The ocean drifts to a warmer climate and produces a global mean surface temperature which is about $4^{\circ} \mathrm{C}$ more (not shown) than that found in the coupled ECHAM5/MPI-OM run. The drift disappears when the $\mathcal{B} \mathbf{y}^{\prime}$-term is installed.

In the second experiment $\mathrm{ABC}$, in which all the three terms in Eq. 1 are included, the MPI-OM model was forced with the same climatological mean fluxes plus fluctuating fluxes produced by EMAD. In the third experiment AB2C, MPI-OM was coupled to EMAD with the variance of white noise doubled.

The three experiments are summarized in Table 1. For each experiment, a spin-up run of about 600 years was carried out. The spin-up runs started from the same initial state obtained from the coupled ECHAM5/MPI-OM model (Jungclaus et al. 2005), after the ocean has reached a more or less statistically stationary state. Following the respective spin-up runs, the experiments were carried out for 200 years. The analysis given below is based on these 200year integrations.

If all the three experiments produce the same climatological mean state (i.e. the same mean sea surface conditions and the same mean surface fluxes) and if this state is identical to that produced by the ECHAM5/MPI-OM model, the time-means of fluctuating fluxes in the three experiments will be zero. In this case, the difference between the experiments $\mathrm{BH}$ and $\mathrm{ABC}$ would describe the effect of fluctuating day-to-day fluxes, and that between the experiments $\mathrm{BH}$ and $\mathrm{AB} 2 \mathrm{C}$ would describe the effect of enhanced fluctuating fluxes.

Unfortunately, the three experiments do not produce exactly the same climatological mean state of the

Table 1 Experiments done with MPI-OM driven by different types of daily fluxes at the sea surface. $\overline{\mathbf{x}}$ denotes the climatological fluxes and $\mathbf{x}^{\prime}$ the flux anomalies predicted by different versions of EMAD model

\begin{tabular}{lll}
\hline Name & Fluxes used & Characteristics \\
\hline $\mathrm{BH}$ & $\overline{\mathbf{x}}+\mathbf{x}^{\prime}, \mathbf{x}_{t}^{\prime}=\mathcal{B} \mathbf{y}_{t}^{\prime},\left(\mathbf{x}^{\prime}=H^{\prime}, \mathbf{y}^{\prime}=S S T^{\prime}\right)$ & No fluctuations, with SST-feedback on heat flux \\
$\mathrm{ABC}$ & $\overline{\mathbf{x}}+\mathbf{x}^{\prime}, \mathbf{x}_{t}^{\prime}=\mathcal{A} \mathbf{x}_{t-1}^{\prime}+\mathcal{B} \mathbf{y}_{t}^{\prime}+\mathcal{C} \mathbf{n}_{t}$ & With fluctuations + feedback \\
$\mathrm{AB} 2 \mathrm{C}$ & $\overline{\mathbf{x}}+\mathbf{x}^{\prime}, \mathbf{x}_{t}^{\prime}=\mathcal{A} \mathbf{x}_{t-1}^{\prime}+\mathcal{B} \mathbf{y}_{t}^{\prime}+2 \times \mathcal{C} \mathbf{n}_{t}$ & With feedback $+2 \times$ fluctuations \\
\hline
\end{tabular}


Fig. 2 Time-mean zonal wind stress in $\mathrm{Pa}$ obtained in a experiment $\mathrm{BH}, \mathbf{b}$ experiment $\mathrm{ABC}$ and $\mathbf{c}$ experiment $\mathrm{AB} 2 \mathrm{C}$
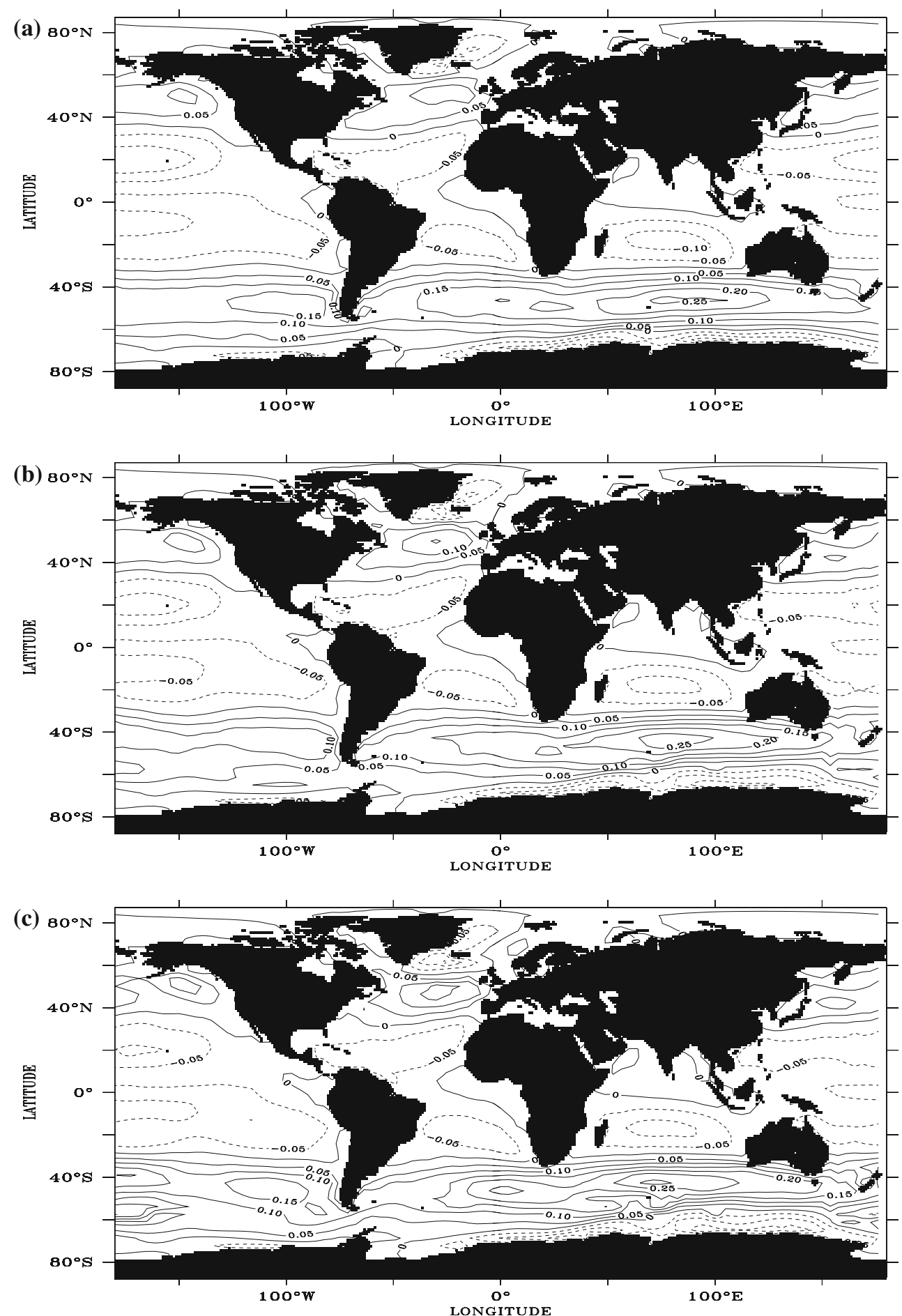

ECHAM5/MPI-OM model. Consequently, the time-mean of fluctuating fluxes in experiments $\mathrm{BH}, \mathrm{ABC}$ and $\mathrm{AB} 2 \mathrm{C}$ are not zero. Moreover, they differ from each other, since the climatological state in experiment $\mathrm{BH}$ can differ from that obtained from experiment $\mathrm{ABC}$ or $\mathrm{AB} 2 \mathrm{C}$. Due to these differences, the changes from experiment $\mathrm{BH}$ to $\mathrm{ABC}$ or from $\mathrm{BH}$ to $\mathrm{AB} 2 \mathrm{C}$ are induced not only by fluctuating fluxes included in experiment $\mathrm{ABC}$ and $\mathrm{AB} 2 \mathrm{C}$, but also by the differences in the time-mean fluxes. A consideration of these time-mean fluxes reveals some notable differences in the time-mean zonal wind stress (Fig. 2). For instance, there is an increase in zonal wind stress in the North Atlantic (at $30^{\circ} \mathrm{W}, 50^{\circ} \mathrm{N}$ ) and a northward shift of the mean zonal wind stress pattern over the Southern Ocean from experiment $\mathrm{BH}$ to experiment $\mathrm{ABC}$ and $\mathrm{AB} 2 \mathrm{C}$. The increase in zonal wind stress in the North Atlantic could be 
relevant, since the wind-driven gyre participates in the meridional salt transport and can therefore affect the MOC (Marti et al. 2008). The shift in the Southern Ocean could contribute to the ACC differences from experiment $\mathrm{BH}$ to $\mathrm{ABC}$ and to $\mathrm{AB} 2 \mathrm{C}$.

To assess the relevance of these non-zero time-mean fluxes, a supplementary experiment, referred to as $\mathrm{BH}^{*}$, is carried out. Experiment $\mathrm{BH}^{*}$ is identical to experiment $\mathrm{BH}$, except that the difference between the time-mean zonal wind stress of experiment BH (Fig. 2a) and that of experiment ABC (Fig. 2b) is added to the climatological mean wind forcing. It will be shown that the time-mean fluxes do not significantly affect the MOC changes and contribute only to a small part of ACC changes. Experiment $\mathrm{BH}^{*}$ is integrated for 350 years.

\section{Changes induced by fluctuating day-to-day fluxes}

\subsection{Time evolutions}

This subsection describes the time evolutions of the oceanic states in different experiments. The consideration is confined to the globally integrated SST and two circulation indices, the Atlantic MOC-index and the ACC-index. The globally integrated SST is considered to describe the effect of the SST-feedback over time. The MOC-index and the ACC-index are chosen, since they characterize major global-scale circulations.

In all experiments, the SST time series are essentially statistically stationary (Fig. 3a). The SST decreases slightly from experiment $\mathrm{BH}$ to experiment $\mathrm{ABC}$ and $\mathrm{AB} 2 \mathrm{C}$. The respective time-mean values are $18.57,18.15$ and $18.12^{\circ} \mathrm{C}$. The spatial distribution of SST changes reveals decreases over most of the subtropical and mid-latitude oceans and increases partially over the North Atlantic from experiment $\mathrm{BH}$ to $\mathrm{ABC}$ and $\mathrm{AB} 2 \mathrm{C}$. The decrease is partly related to the increase in frequency and depth of convective events in the subtropical and mid-latitude oceans (see Sect. 4.4), which bring cold dense water down. The fluctuating fluxes also enhance the SST variability.

Figure $3 \mathrm{~b}$ shows the time series of the MOC-index, defined as the maximum of the Atlantic meridional overturning streamfunction near $30^{\circ} \mathrm{N}$ at about $1,220 \mathrm{~m}$. The experiment $\mathrm{BH}$ (dotted line), which does not include fluctuating fluxes, reveals little variability in the MOC. Stronger variations are obtained by including fluctuations (solid line) in experiment $\mathrm{ABC}$. The variations are strongest in experiment $\mathrm{AB} 2 \mathrm{C}$ (dashed line) where the variance of the stochastic forcing is doubled.

Not only the variability but also the time mean of the MOC-index changes from experiment to experiment. This is further summarized in Table 2. The smallest value of (a) 21

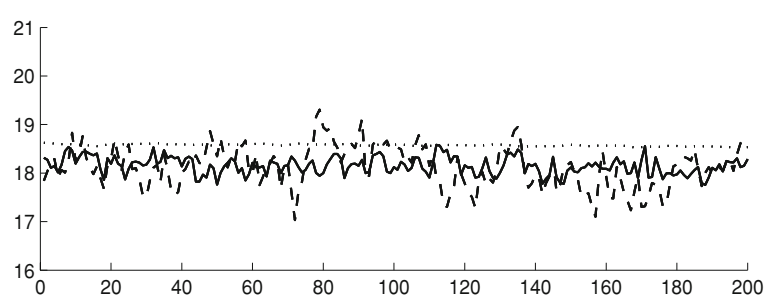

(b) 40

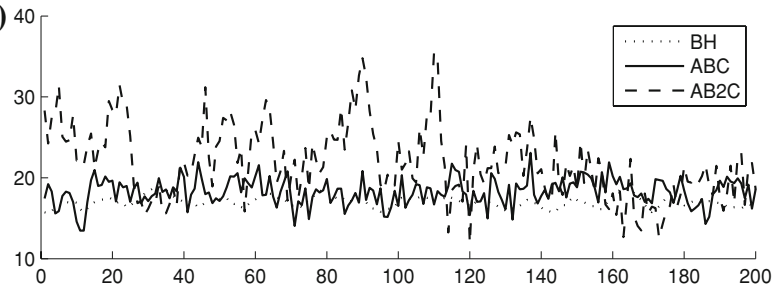

(c) 300

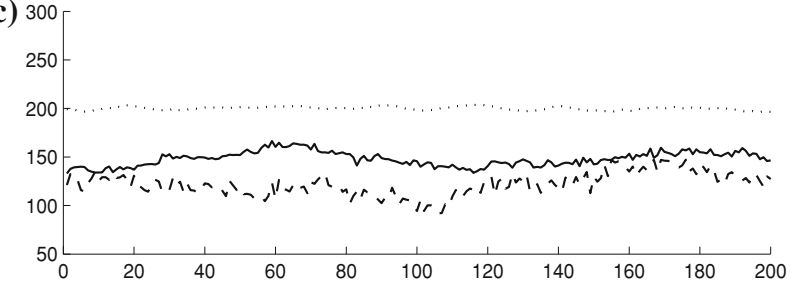

Fig. 3 Yearly time series of a globally integrated sea surface temperature in ${ }^{\circ} \mathbf{C}, \mathbf{b}$ the maximum of Atlantic meridional overturning streamfunction located near $30^{\circ} \mathrm{N}$ in Sv (MOC-index) and c Drake Passage mass transport in Sv (ACC-index) obtained from experiment $\mathrm{BH}$ (dotted), $\mathrm{ABC}$ (solid) and $\mathrm{AB} 2 \mathrm{C}$ (dashed)

Table 2 200-year means of MOC-index and ACC-index in Sv in different experiments

\begin{tabular}{lll}
\hline Experiment name & MOC-index & ACC-index \\
\hline BH & 17.1 & 200 \\
ABC & 18.3 & 148 \\
AB2C & 21.8 & 122 \\
ECHAM5/MPI-OM & 18.0 & 186 \\
\hline
\end{tabular}

about $17 \mathrm{~Sv}$ is obtained from experiment $\mathrm{BH}$. Inclusion of fluctuations leads to an increase of about $18 \mathrm{~Sv}$ in experiment $\mathrm{ABC}$. Experiment $\mathrm{AB} 2 \mathrm{C}$, in which the strongest MOC of about $22 \mathrm{~Sv}$ is found, further confirms that the $1-\mathrm{Sv}$ increase from experiment $\mathrm{BH}$ to experiment $\mathrm{ABC}$ is caused by the fluctuating component in the fluxes. The time-mean of the MOC-index of a 200-year time series of the coupled ECHAM5/MPI-OM simulation is also comparable to that of experiment $\mathrm{ABC}$ (last row in Table 2).

Figure $3 \mathrm{c}$ shows the time series of the ACC-index defined as the mass transport through the Drake Passage. There is an enhancement of variability through fluctuations in experiment $\mathrm{ABC}$ and $\mathrm{AB} 2 \mathrm{C}$ (solid line and dashed lines respectively). Concerning the time-mean (see also Table 2), a mean transport of about $200 \mathrm{~Sv}$ is obtained in experiment $\mathrm{BH}$. This value is too high relative to the 
observed value of about 120-150 Sv (Nowlin and Klinck 1986; Cunningham et al. 2003). The transport reduces to about $148 \mathrm{~Sv}$ in experiment $\mathrm{ABC}$ and to about $122 \mathrm{~Sv}$ in $\mathrm{AB} 2 \mathrm{C}$. The strength of the net mass transport through the Drake Passage reflects well the strength of the zonal current in the entire Southern Ocean (not shown). Table 2 shows that a stronger MOC corresponds to a weaker ACC. The correspondence concerns only the time-mean values. The variability of the ACC-index is not correlated to that of the MOC-index.

To have an idea about how much of the changes listed in Table 2 are caused by the differences in the time-mean zonal wind stress shown in Fig. 2, the time-mean values of the MOC-index and the ACC-index are calculated from the last 200 years of experiment $\mathrm{BH}^{*}$. They amount to 17.2 and $180 \mathrm{~Sv}$, respectively. The first number suggests that the increase in zonal wind stress in the North Atlantic from Fig. 2a and $\mathrm{b}$ is not responsible for the 1-Sv MOC increase found by comparing experiment $\mathrm{ABC}$ with experiment $\mathrm{BH}$. Instead, the $1-\mathrm{Sv}$ increase is likely caused by the fluctuating fluxes included in experiment $\mathrm{ABC}$. The second number suggests that the $\mathrm{ACC}$ change from experiment $\mathrm{BH}$ to $\mathrm{ABC}$ is partly due to the northward shift in the timemean zonal wind stress shown in Fig. 2b. However, if the effect of time-mean wind stress and that of fluctuating fluxes can be linearly superimposed, the effect due to the time-mean zonal wind stress is smaller than that of the fluctuating fluxes.

For the comparison, the values of the MOC- and ACCindices in ECHAM5/MPI-OM are shown in Table 2 (last row). If the climatological mean state in the ECHAM5/ MPI-OM model is identical to that in the hybrid EMAD/ MPI-OM model, the values obtained from experiment ABC would be close to those shown in the last row. One finds a good agreement for the MOC-index, but not as good an agreement for the ACC-index. This further confirms that the circulation in the MPI-OM model is more sensitive to the time-mean zonal wind stresses in the Southern Ocean than those in the North Atlantic.

\subsection{Changes in the Atlantic meridional overturning circulation}

The different formulations of the surface fluxes result in different Atlantic MOCs (Fig. 4). The difference concerns not only the strength that is described by the MOC-index in Fig. 3 and Table 2, but also the structure. When the MPI$\mathrm{OM}$ is driven by the climatological fluxes plus the oceanic feedbacks (experiment $\mathrm{BH}$ ), an overturning cell of around $2,800 \mathrm{~m}$ and $17 \mathrm{~Sv}$ maximum strength is obtained (Fig. 4a). In experiment ABC (Fig. 4b), the overturning cell is stronger and extends a couple of hundreds of meters down to the deep ocean compared to that of $\mathrm{BH}$. When the stochastic forcing is doubled, the overturning circulation further strengthens and deepens (Fig. 4c). The deepening of the overturning cell is accompanied by the weakening of the Antarctic Bottom Water cell and the retreat of the Antarctic Bottom Water (AABW). In experiment $\mathrm{AB} 2 \mathrm{C}$, the penetration of $\mathrm{AABW}$ into the abyssal North Atlantic is severely blocked. The spatial structure of the Atlantic MOC in experiment $\mathrm{ABC}$ is comparable to that produced by the ECHAM5/MPI-OM model (not shown) and that obtained from an ensemble of coupled AOGCMs (Stouffer et al. 2006).

To make sure that the $1-\mathrm{Sv}$ increase in MOC is statistically significant, a $t$ test is carried out. The null hypothesis that the maximum overturning in experiment $\mathrm{BH}$ equals that in experiment $\mathrm{ABC}$ is considered. The null hypothesis is rejected with $1 \%$ risk.

To show that the above described structural changes do not result from the different time-mean zonal wind stress, the mean Atlantic overturning streamfunction obtained from the last 200 years of experiment $\mathrm{BH}^{*}$ is shown in Fig. 5. Both the strength and the structure are comparable to the streamfunction obtained from experiment $\mathrm{BH}$.

\subsection{Changes in the density fields}

To understand whether and to what extent fluctuating fluxes change the mean circulation via changing density structures, consider first the situation at the surface. Figure 6a shows the zonal-mean meridional profiles of surface density in the Atlantic sector. The large differences at the high northern latitudes result from different climatological mean states in the Arctic: the Arctic becomes more saline from experiment $\mathrm{BH}$ to experiment $\mathrm{ABC}$ and $\mathrm{AB} 2 \mathrm{C}$ (not shown). In the North Atlantic from about $40^{\circ} \mathrm{N}$ to $75^{\circ} \mathrm{N}$, it is difficult to relate changes in the meridional density gradient to the MOC changes found in experiments $\mathrm{BH}$, $\mathrm{ABC}$ and $\mathrm{AB} 2 \mathrm{C}$. In the south from $30^{\circ} \mathrm{S}$ to $60^{\circ} \mathrm{S}$, the meridional gradient in experiment $\mathrm{BH}$ is stronger than that in experiment $\mathrm{ABC}$ and $\mathrm{AB} 2 \mathrm{C}$, as indicated by the dotted line $(\mathrm{BH})$ which is below the solid $(\mathrm{ABC})$ and dashed (AB2C) lines north of about $45^{\circ} \mathrm{S}$ and above them, south of $45^{\circ} \mathrm{S}$. The change from experiment $\mathrm{ABC}$ to $\mathrm{AB} 2 \mathrm{C}$ (solid and dashed lines) is less clear. Following the previous studies (e.g. Russell et al. 2006) suggesting that the ACC is related to the density gradient in deeper layers, in particular to the density gradient integrated over the sill depth, density changes in the oceanic interior were considered.

Indeed the effects of fluctuating fluxes can be traced down to the deep ocean. Figure 7 a shows the in situ density in experiment $\mathrm{BH}$ at $1,365 \mathrm{~m}$. The density field is characterized by higher density in the Atlantic and the Southern Oceans than in the Pacific and the Indian Oceans. To describe the changes in the density gradient induced by 
Fig. 4 Spatial structure of the time-mean Atlantic MOC in Sv $\mathrm{BH},(\mathbf{b}) \mathrm{ABC}$, (c) $\mathrm{AB} 2 \mathrm{C}$ in different experiments. (a)
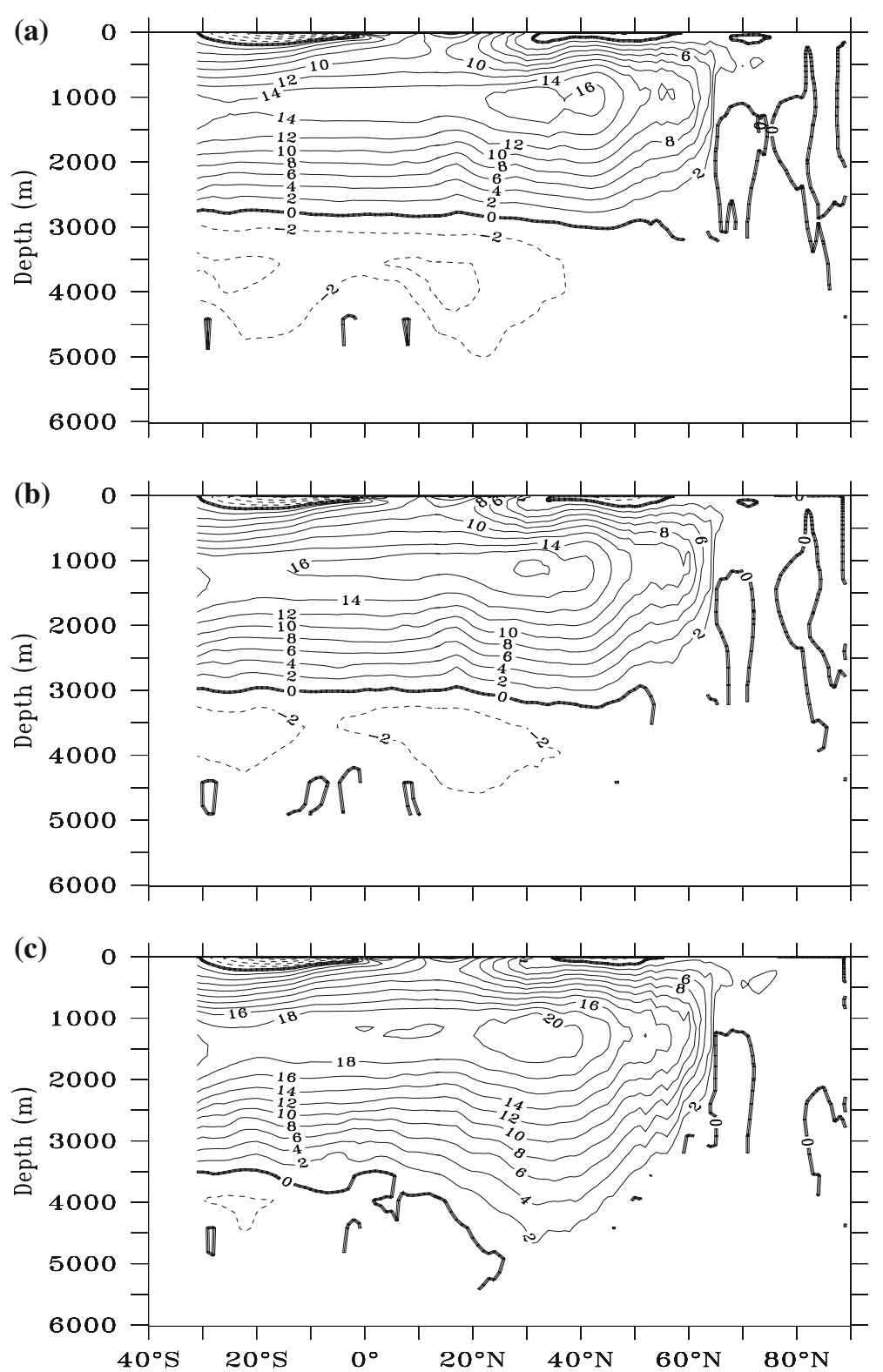

Fig. 5 Spatial structure of the time-mean Atlantic MOC in $\mathrm{Sv}$ in experiment $\mathrm{BH}^{*}$

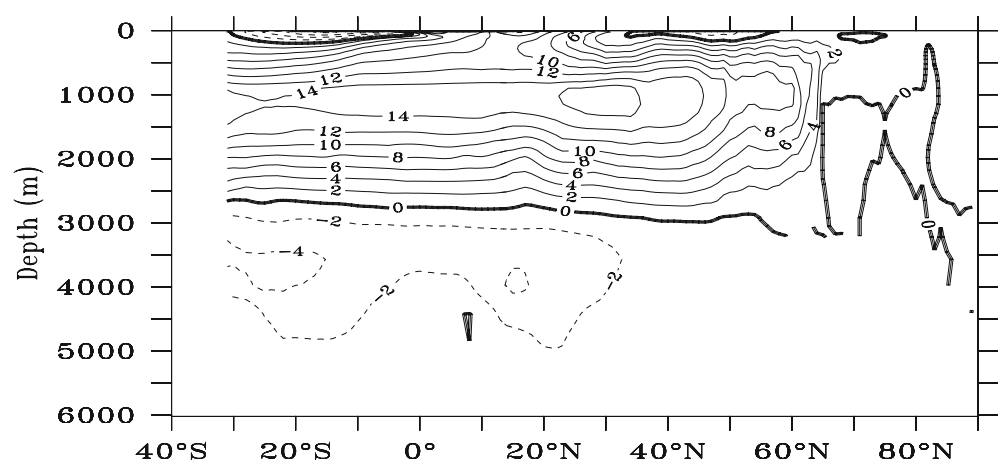

fluctuating fluxes, the differences between experiments $\mathrm{ABC}$ and $\mathrm{BH}$ and between $\mathrm{AB} 2 \mathrm{C}$ and $\mathrm{BH}$ are shown in Fig. $7 \mathrm{~b}$ and $\mathrm{c}$, respectively. The dominant feature of the density changes is the zonally oriented density increases centered near $40^{\circ} \mathrm{S}$ and density decreases further south. The amplitudes of the density increases are larger than those of 


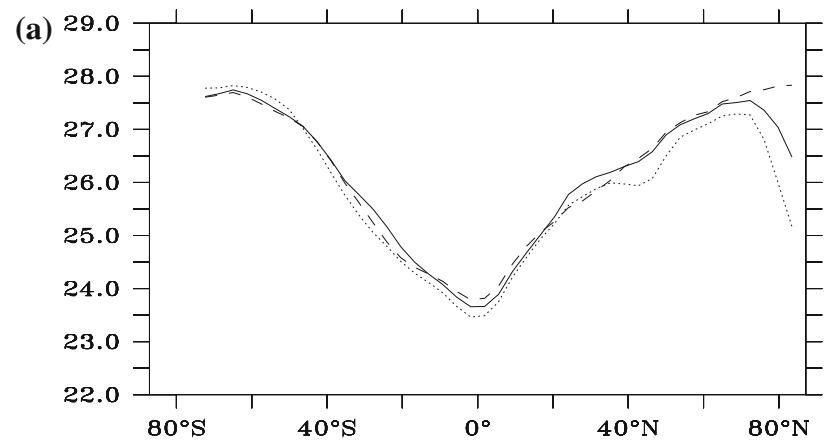

(b)

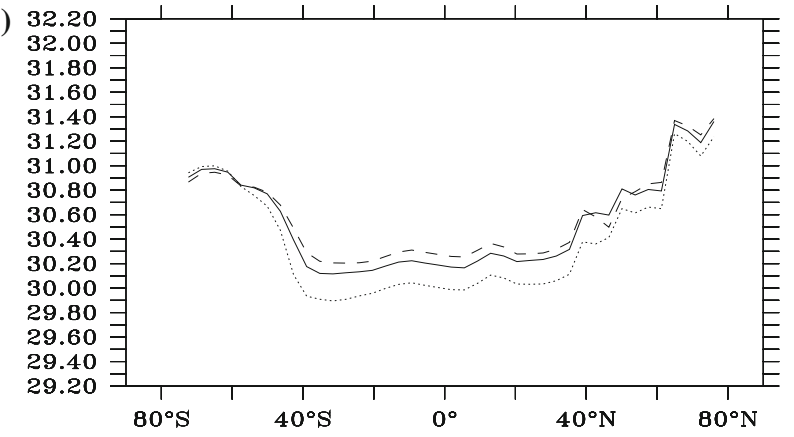

Fig. 6 Meridional profiles of the zonal mean of surface density and the zonal mean of depth-integrated in situ density in the Atlantic sector obtained from experiment $\mathrm{BH}$ (dotted), $\mathrm{ABC}$ (solid) and $\mathrm{AB} 2 \mathrm{C}$ (dashed). The depth integration starts from 1,220 m for experiments $\mathrm{BH}, \mathrm{ABC}$ and $\mathrm{AB} 2 \mathrm{C}$. The Atlantic sector covers the oceanic region from $70^{\circ} \mathrm{W}$ to $10^{\circ} \mathrm{E}$ and hence includes the Drake passage. Unit is $\mathrm{kg} \mathrm{m}^{-3}$. (a) Surface density $\left(\mathrm{kg} / \mathrm{m}^{3}\right)$, (b) Depth-integrated in-situ density $\left(\mathrm{kg} / \mathrm{m}^{3}\right)$

decreases. These changes lead to a reduction in the meridional density gradient in the Southern Ocean and hence a weakening of the ACC.

The density changes in the North Atlantic are more subtle. From the difference AB2C-BH shown in Fig. 7c, one can identify a few isolines in the Atlantic north of $40^{\circ} \mathrm{N}$ that reveal strong tilt in the north-south direction. These isolines suggest an increase in the zonal density gradient that are by geostrophic relation consistent with the large increase of the MOC of more than $4 \mathrm{~Sv}$ from experiment $\mathrm{BH}$ to $\mathrm{AB} 2 \mathrm{C}$. However, this feature does not show up clearly in the difference ABC-BH (Fig. 7b).

A further search for a clear relation between changes in density distribution and changes in the Atlantic MOC leads to the consideration of the depth-integrated in situ density. This quantity was shown to be related to the strength of the MOC in previous studies (Hughes and Weaver 1994; Thorpe et al 2001). Figure $6 \mathrm{~b}$ shows the zonal mean of depth-integrated in situ density in the Atlantic sector. The increase of the density equatorward of about $40^{\circ}$ from experiment $\mathrm{BH}$ to $\mathrm{ABC}$ and $\mathrm{AB} 2 \mathrm{C}$ is related to the change in the climatological mean state, which becomes colder in experiment $\mathrm{ABC}$ and $\mathrm{AB} 2 \mathrm{C}$, relative to that in experiment $\mathrm{BH}$. The cooling is partly due to the increase in frequency and depth of convective events (see Sect. 4.4). Regarding the meridional gradient, the meridional gradients between $40^{\circ} \mathrm{S}$ and $40^{\circ} \mathrm{N}$ and between $40^{\circ} \mathrm{N}$ and $60^{\circ} \mathrm{N}$ do not change much. However, small changes in density difference between northern North Atlantic and the South Atlantic are possible. After calculating the density difference between different latitudinal strips in the North and South Atlantic, we found that the density difference between the northern strip extending from $55^{\circ} \mathrm{N}$ to $60^{\circ} \mathrm{N}$ and the southern strip extending from $45^{\circ} \mathrm{S}$ to $50^{\circ} \mathrm{S}$ increases with the MOC from $0.11 \mathrm{~kg} \mathrm{~m}^{-3}$ in experiment $\mathrm{BH}$ to $0.12 \mathrm{~kg} \mathrm{~m}^{-3}$ in experiment $\mathrm{ABC}$ and to $0.13 \mathrm{~kg} \mathrm{~m}^{-3}$ in experiment $\mathrm{AB} 2 \mathrm{C}$. A similar north-south density difference was considered in studies by Rahmstorf (1996) and Thorpe et al (2001).

In the Southern Ocean, the meridional gradient of the depth-integrated density (Fig. 6b) is reduced. Expressed in terms of the density difference between $40^{\circ} \mathrm{S}$ and $60^{\circ} \mathrm{S}$, one finds decreases from $1.02 \mathrm{~kg} \mathrm{~m}^{-3}$ in experiment $\mathrm{BH}$ (dotted) to $0.77 \mathrm{~kg} \mathrm{~m}^{-3}$ in experiment $\mathrm{ABC}$ (solid) and to $0.63 \mathrm{~kg} \mathrm{~m}^{-3}$ in experiment $\mathrm{AB} 2 \mathrm{C}$ (dashed). The reduction of meridional gradient is more strongly related to the increase in density around $40^{\circ} \mathrm{S}$ than to the decrease in density around $60^{\circ} \mathrm{S}$. These changes in meridional density distribution are related to the changes in ACC in different experiments by the geostrophic relation.

\subsection{Changes in the vertical mixing}

In this section, the way surface fluxes alter the density in the deep ocean is examined. It will be shown that surface fluxes change the density via vertical mixing. Before dealing with these mixing changes, consider first the timemean mixing, as described by the time-mean vertical diffusion coefficient $K$ for experiment BH at $285 \mathrm{~m}$ depth in Fig. 8a and at $900 \mathrm{~m}$ depth in Fig. 9a. In GIN Seas and along and near the Antarctic coast in the Atlantic sector and south of the South America, large time-mean values of $K$ and mean convection depth (Fig. 10a) are found, which is also the case in the coupled ECHAM5/MPI-OM model. These regions are the most unstable regions of the ocean model. Elsewhere, the modelled ocean is much more stable.

A maximum of $K$ is also found at $285 \mathrm{~m}$ in the north Pacific just west of the date line between $50^{\circ} \mathrm{N}$ and $60^{\circ} \mathrm{N}$ (Fig. 8a). This maximum disappears at $900 \mathrm{~m}$ in Fig. 9a. The map of the mean depth of convection (Fig. 10a) suggests that the convection related to this maximum is shallower than $600-650 \mathrm{~m}$.

Generally, $K$ is smaller than $0.002 \mathrm{~m}^{2} \mathrm{~s}^{-1}$ in most part of the ocean at $900 \mathrm{~m}$ and decreases with depth to values smaller than $10^{-4} \mathrm{~m}^{2} \mathrm{~s}^{-1}$ below $2,500 \mathrm{~m}$. These values should be compared with the observational range of $10^{-6}$ to $10^{-3} \mathrm{~m}^{2} \mathrm{~s}^{-1}$ reported from interior oceanic regions 


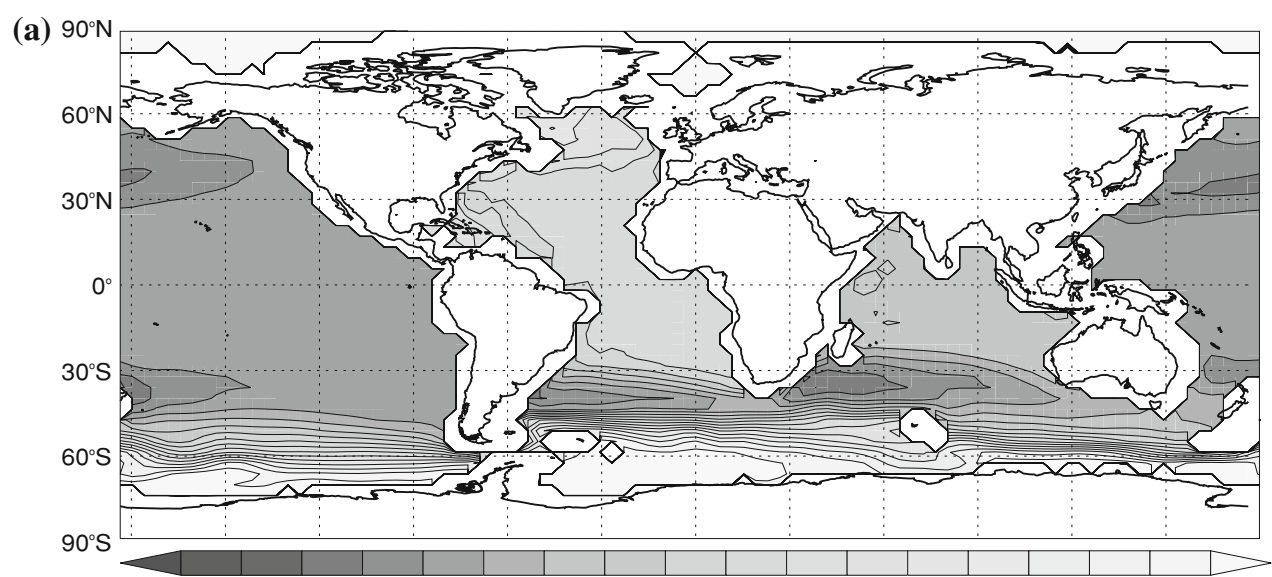

33.5033 .5533 .6033 .6533 .7033 .7533 .8033 .8533 .9033 .9534 .0034 .0534 .1034 .1534 .2034 .2534 .3034 .35

(b)
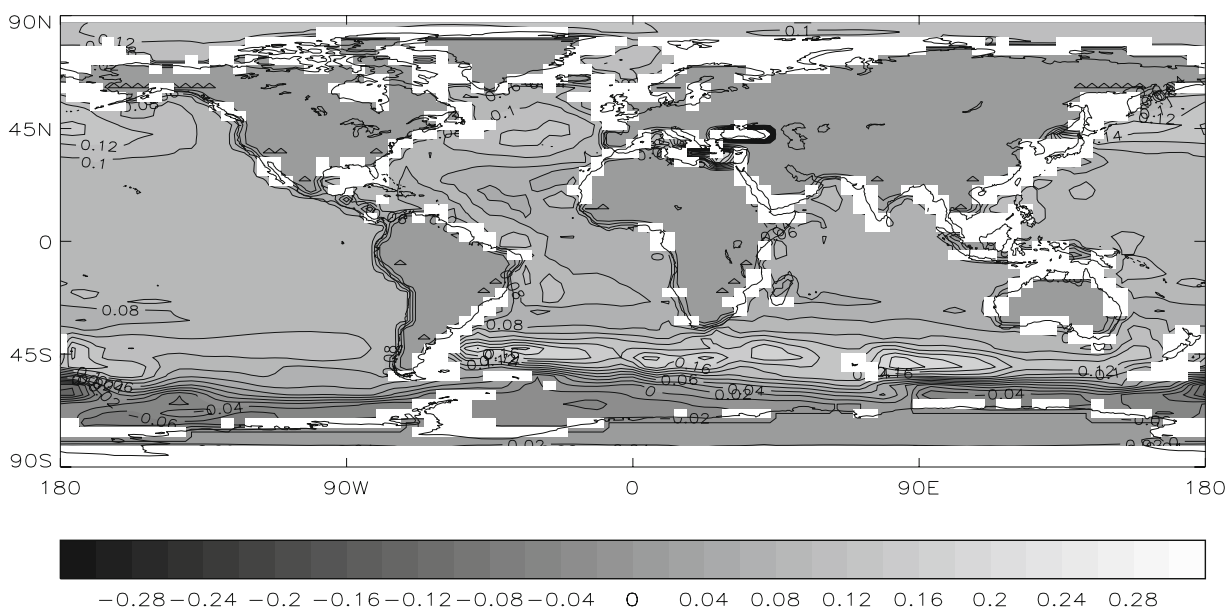

(c)

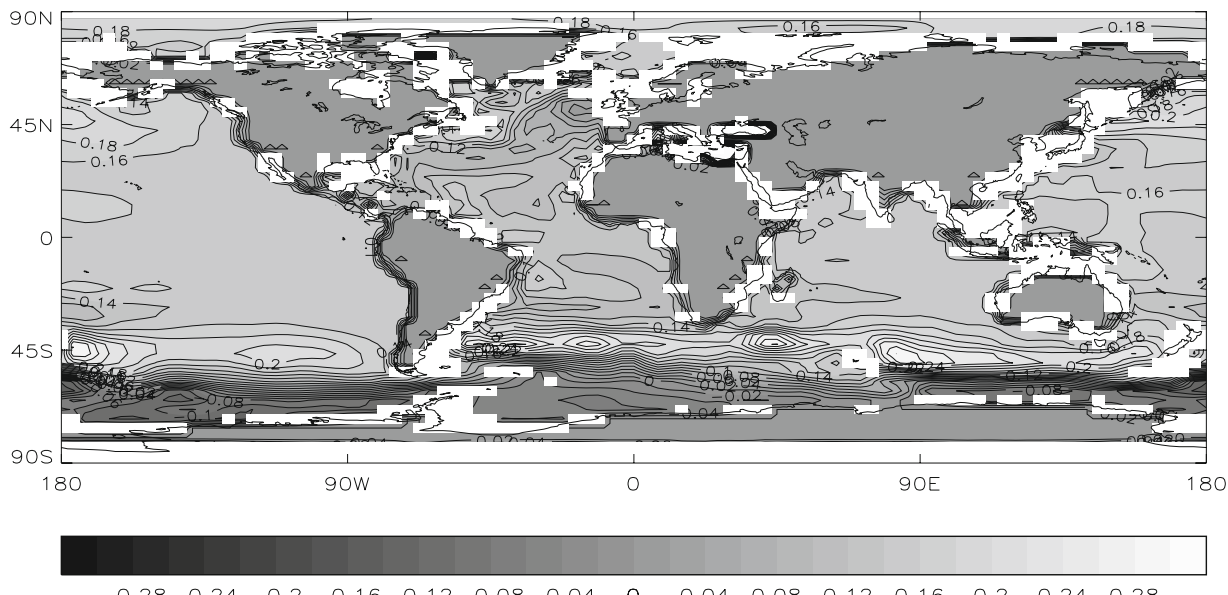

Fig. 7 Horizontal distributions of in situ density at $1,365 \mathrm{~m}$ in $\mathrm{kg} \mathrm{m}^{-3}$ for a the time-mean in experiment $\mathrm{BH}$ and $\mathbf{b}$ the difference between experiments $\mathrm{ABC}$ and $\mathrm{BH}$ and $\mathbf{c}$ between experiments $\mathrm{AB} 2 \mathrm{C}$ and $\mathrm{BH}$

(Ledwell et al. 1993, 2000; Moum et al. 2002; Gregg et al. 2003; Sloyan 2005).

Consider now the changes in the vertical mixing due to different surface fluxes. In the following, the effect of the fluctuating fluxes is indicated by the difference in $K$ (ABC$\mathrm{BH})$ obtained from experiment $\mathrm{ABC}$ and $\mathrm{BH}$. The effect of the fluctuations with enhanced variance is obtained by comparing the difference $\mathrm{AB} 2 \mathrm{C}-\mathrm{BH}$ with the difference 

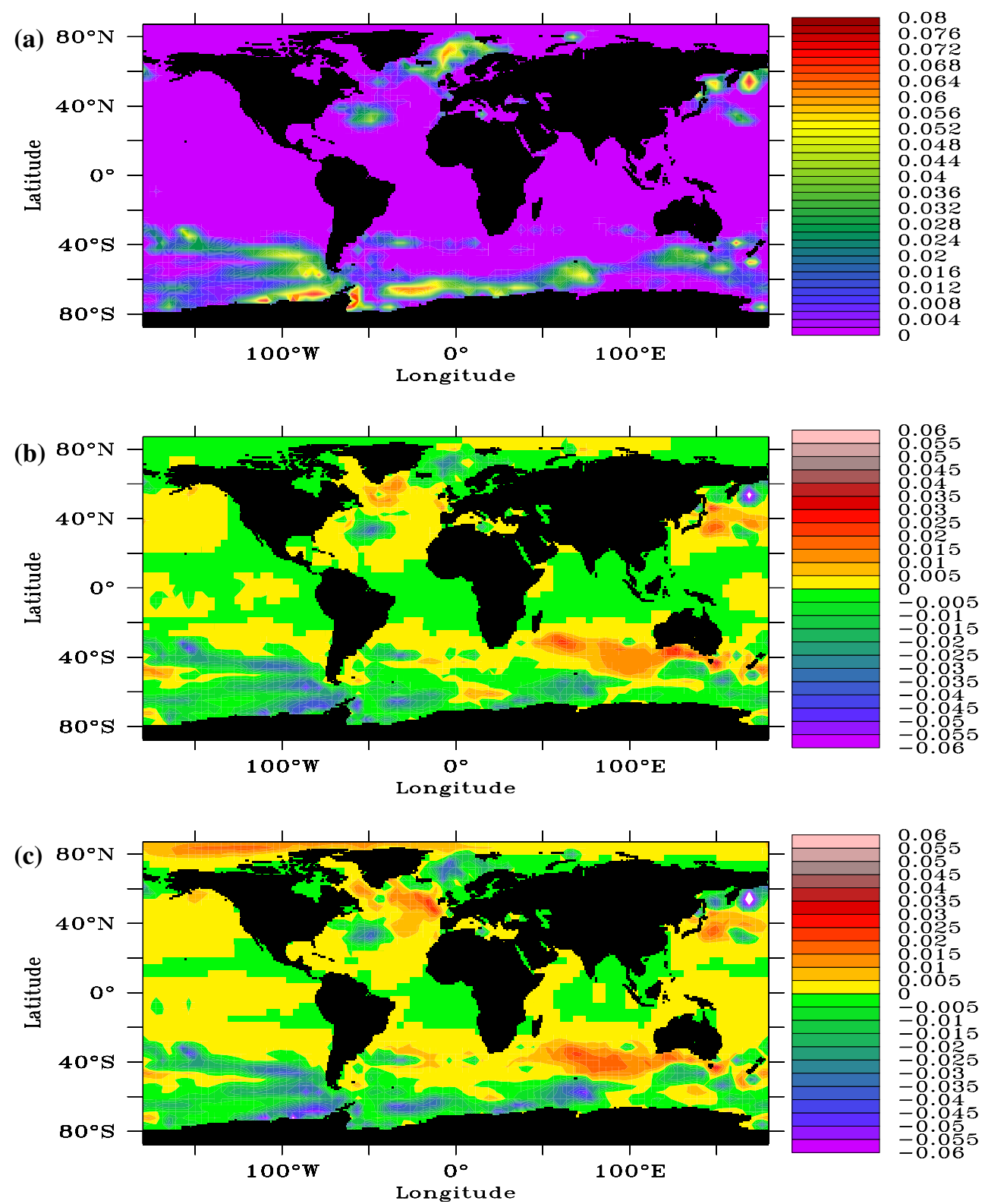

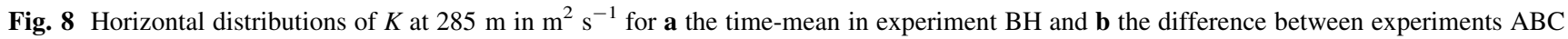
and $\mathrm{BH}$ and $\mathbf{c}$ between experiments $\mathrm{AB} 2 \mathrm{C}$ and $\mathrm{BH}$

ABC-BH. The possible effect of the time-mean zonal wind stress on changes in $K$ is small and will be discussed at the end of this section.

Figure $8 \mathrm{~b}$ shows the difference in $K$ (ABC-BH) at $285 \mathrm{~m}$ depth, induced by the fluctuations. Outside the tropics, where large changes of $K$ are found, there is a striking correspondence between the distribution of the time-mean frequency and depth of convective events shown in Figs. 8a and 10a and the distribution of the changes in $K$ from experiment $\mathrm{BH}$ to $\mathrm{ABC}$ shown in Fig. $8 \mathrm{~b}$ in the MPI-OM model: the strong decreases in $K$ are found in the regions where the time-mean values of $K$ are large, indicating frequent occurrence of convective events due to mostly unstable stratification. These regions consist of the GIN Seas, an area centered near $50^{\circ} \mathrm{W}$ and $35^{\circ} \mathrm{N}$ in the North Atlantic, the areas south of the South American continent and west and east of the Antarctic Peninsula. The increases in $K$, on the other hand, are found in regions where the time-mean values of $K$ are generally small and convective events are less frequent due to mostly stable stratification. In the North Atlantic, an area with increases in $K$ is found between $40^{\circ} \mathrm{N}$ to $60^{\circ} \mathrm{N}$, south of the GIN Seas. There, the time-mean values of $K$ are generally small, apart from the areas close to the Irminger Sea which will be discussed at the end of this section. In the Southern Ocean, increases in $K$ are found mainly in the latitude band 

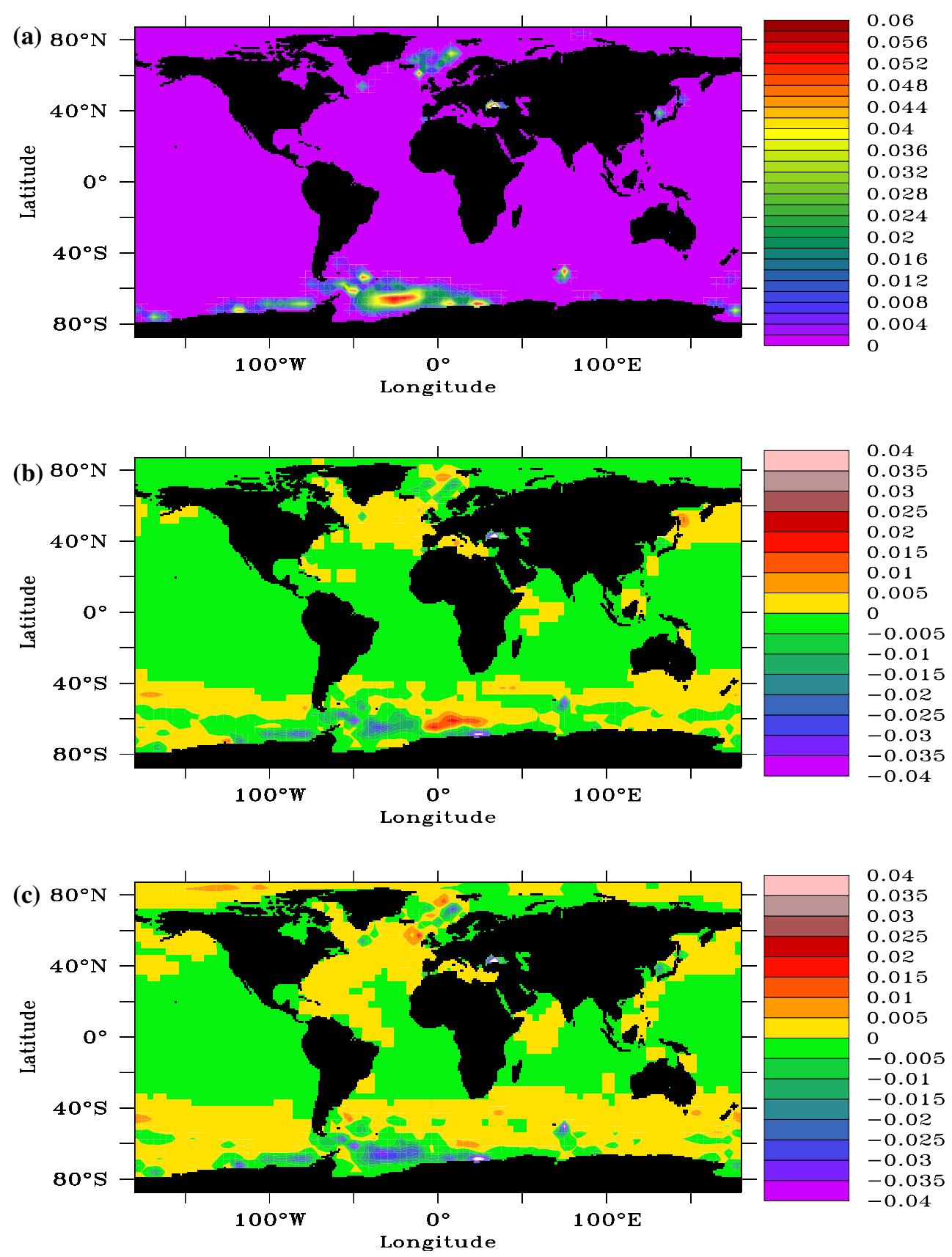

Fig. 9 Same as Fig. 8, but for $K$ at $900 \mathrm{~m}$

from $20^{\circ} \mathrm{S}$ to $50^{\circ} \mathrm{S}$. This correspondence between the timemean values of $K$ and changes in $K$ can also be seen in experiment AB2C (Fig. 8c).

At $900 \mathrm{~m}$ (Fig. 9b), the correspondence between the time-mean mixing and the changes in the convective mixing is also noticeable poleward of about $40^{\circ}$. In particular, the decreases in $K$ are mainly located in regions with large values of the time-mean mixing shown in Fig. 9a. Overall, the magnitudes of mixing changes are much smaller at $900 \mathrm{~m}$ (Fig. 9b, c) than at $285 \mathrm{~m}$ (Fig. 8b, c). The areas with enhanced mixing in experiment $\mathrm{ABC}$
(Fig. 9b) is enlarged when the strength of stochastic fluctuations is doubled in experiment $\mathrm{AB} 2 \mathrm{C}$ (Fig. 9c): the patchy structure over the Southern Ocean in Fig. 9b becomes more uniform in Fig. 9c. Mixing structures similar to Fig. 9 but with smaller amplitudes can be found down to about 2,500-3,000 m. Further below, the mixing signal is much less zonally oriented.

Following the definition of $K$, the above described changes in $K$ are related to changes in the frequency of convective events. Changes in the mean depth of convective events are described in Fig. 10b and c. The largest 

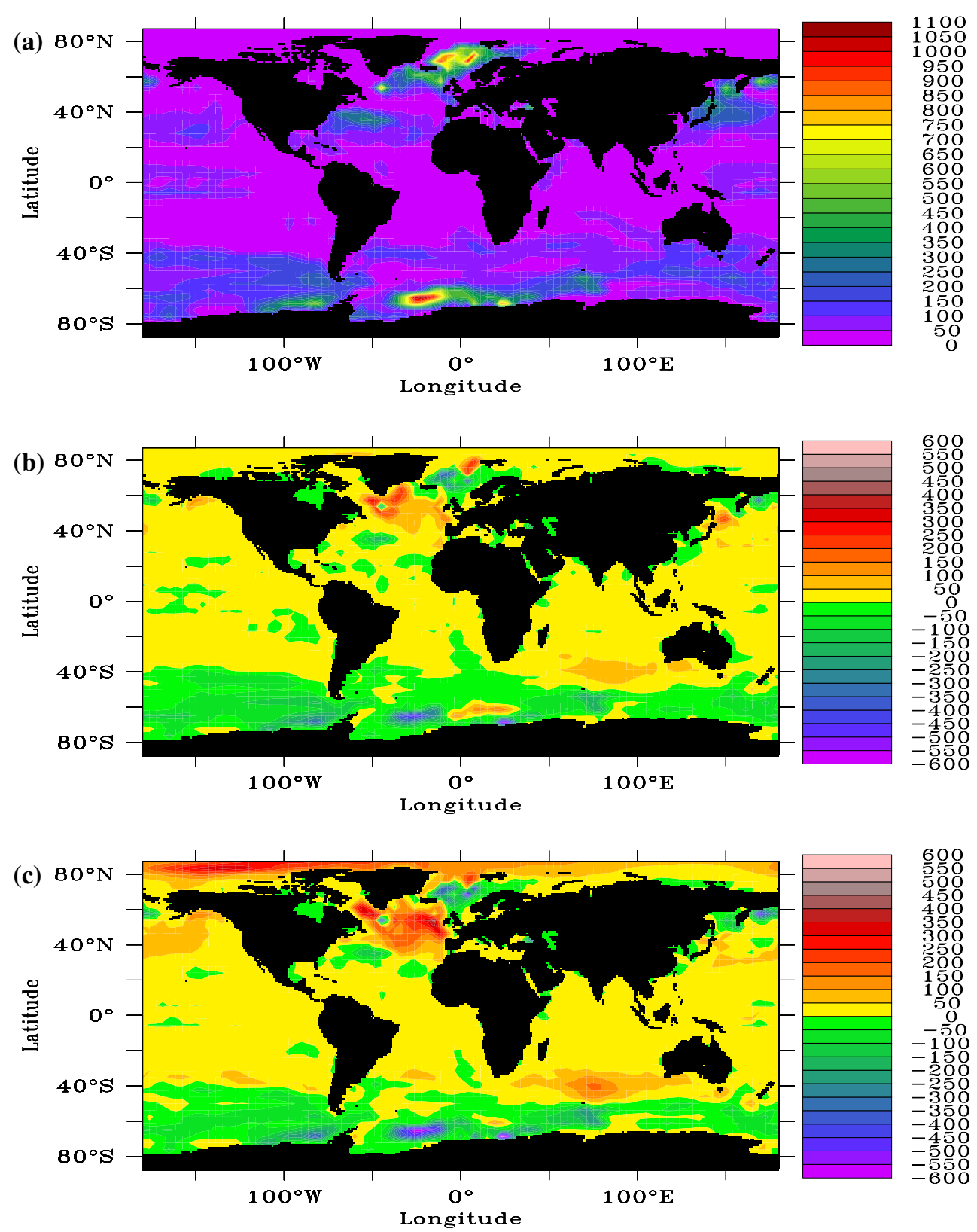

Fig. 10 Horizontal distributions of mean convection depth in $\mathrm{m}$ for $\mathbf{a}$ the time-mean in experiment $\mathrm{BH}$ and $\mathbf{b}$ the difference between experiments $\mathrm{ABC}$ and $\mathrm{BH}$ and $\mathbf{c}$ between experiments $\mathrm{AB} 2 \mathrm{C}$ and $\mathrm{BH}$

changes in the mean convection depth are about $300 \mathrm{~m}$. A comparison of Fig. 10b and c with Fig. $8 \mathrm{~b}$ and c suggests that, apart from the tropical oceans, an increase (a decrease) in the frequency of convective events corresponds to an increase (a decrease) in the depth of convective events. Since the regions with small (large) time-mean values of $K$ and shallow (deep) mean convection represent regions which are often stably (unstably) stratified, one can conclude that the fluctuating fluxes tend to increase the convective mixing over mostly stable ocean and decrease convective mixing over mostly unstable ocean. Moreover, an increase (a decrease) in convective mixing is accomplished by an increase (a decrease) in both frequency and depth of convective events.

The above described mixing changes can be responsible for the density changes described in Sect. 4.3. As the enhanced vertical mixing is related to an increase in the frequency and the depth of convective events and these events generally bring dense water down, the increase in vertical mixing in the midlatitudes found in experiments $\mathrm{ABC}$ and $\mathrm{AB} 2 \mathrm{C}$ can lead to an increase in density there. In the Atlantic, the increase in the vertical mixing near the northern strip $55^{\circ} \mathrm{N}-60^{\circ} \mathrm{N}$ is stronger than that in the southern strip $45^{\circ} \mathrm{S}--50^{\circ} \mathrm{S}$. This can lead to the increase of 


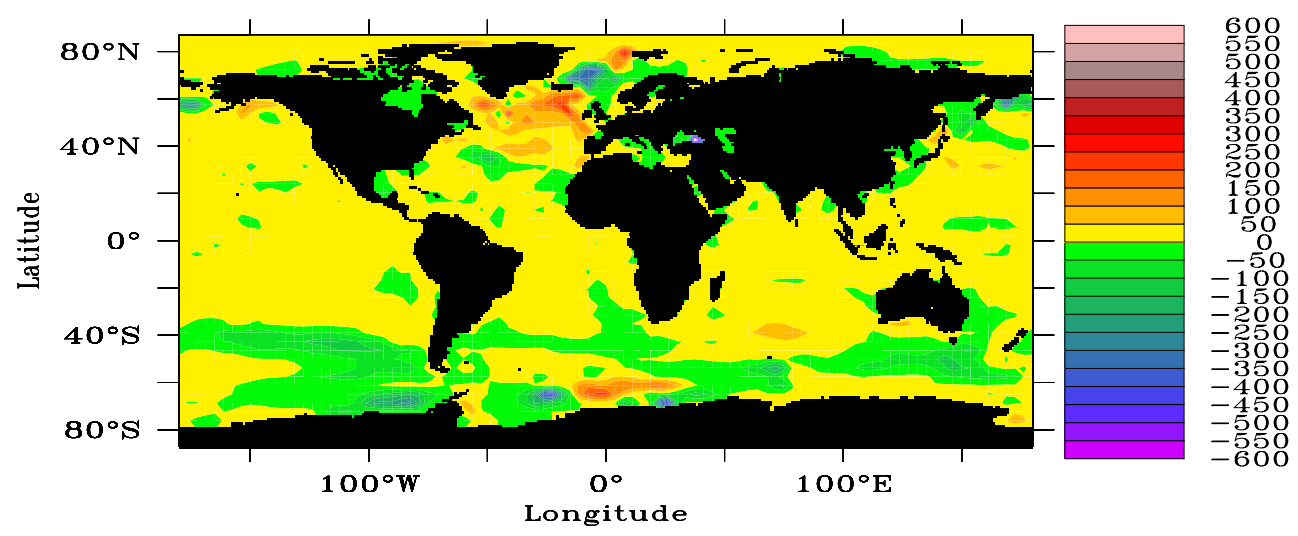

Fig. 11 Horizontal distribution of the change in the mean convection depth in m between experiments $\mathrm{ABC}$ and $\mathrm{BH}^{*}$

the density difference between the two strips from experiment $\mathrm{BH}$ to experiment $\mathrm{ABC}$ and $\mathrm{AB} 2 \mathrm{C}$, which is related to the respective MOC increases. The large-scale increase in the vertical mixing in the Southern Ocean can be responsible for the increase in density near $40^{\circ} \mathrm{S}$, which results in a weaker meridional density gradient and a weaker ACC.

There exists a few spots where the change in $K$ is not clearly related to the mean stratification, for instance west of Svalbard and also in the Arctic.

Note that the distribution of changes in the convection depth (Fig. 10b, c) compares less well with changes in $K$ at $900 \mathrm{~m}$ (Fig. 9b, c) than with changes at $285 \mathrm{~m}$ (Fig. 8b, c). This is because Fig. 10 represents the mean convection depth, rather than the depth of individual convective events. Apart from a few exceptions at high-latitudes, convective events are mostly shallower than a few hundred meters. The changes in convection depth due to fluctuating fluxes are generally smaller than $300 \mathrm{~m}$. Thus, Fig. 10b and $\mathrm{c}$ reflect mainly the changes related to convections shallower than $900 \mathrm{~m}$.

Also in tropical oceans, the changes in convective activity (Fig. 10b, c) do not correspond to changes in $K$ (Figs. 8b, c and 9b, c) in tropical oceans. There, one finds increases in the convective depth, even though the vertical mixing is reduced. This is because convective events are confined to the upper $60 \mathrm{~m}$ in the tropical and subtropical Atlantic and Indian Oceans and to the upper $100 \mathrm{~m}$ in the tropical and subtropical Pacific, but can reach a few hundred meters in the extra-tropical regions. As the convective events triggered by the fluctuating daily fluxes are confined to a shallow surface layer, the decrease in $K$ in the tropics below, say, 100 m, as seen in Figs. 8b, c and 9b, c is likely caused by the $R i$-dependent mixing, rather than the convective mixing.

The above described mixing changes are mainly due to fluctuating fluxes. The effect of time-mean fluxes is mostly secondary. This is shown by the difference in the mean convection depth found in the experiments $\mathrm{ABC}$ and $\mathrm{BH}^{*}$ (Fig. 11). Different from Fig. 10b which shows changes due to fluctuating fluxes and the difference in the timemean zonal wind stress, the effect due to different timemean zonal wind stress is eliminated in Fig. 11. Since Fig. $10 \mathrm{~b}$ is very close to Fig. 11, the effect due to different time-mean zonal wind stress must be small. An exception is the change near the Irminger Sea. In this region, the mechanism which alters the MOC through the wind-driven gyre (Marti et al. 2008) can be at work. The stronger timemean zonal wind stress in experiment $\mathrm{ABC}$ can transport more salt northward, whereby enhancing the surface density and triggering more often convective events. This is likely the reason, why large increases in the frequency and depth of convective events are found in the Irminger Sea (Fig. 8b and Fig. 10b), where, if the effect of fluctuating fluxes dominated, a decrease in the frequency and depth of convective events was expected.

\section{Conclusions and discussion}

The MPI-OM model coupled to the empirical flux model EMAD is used to isolate the effect of fluctuating fluxes. It is found that fluctuating daily fluxes can produce a $1-\mathrm{Sv}$ increase in the strength of the Atlantic MOC, which is about $7 \%$ of the MOC obtained without the fluctuating fluxes, and a 32-Sv-reduction of the ACC, which is about $16 \%$ of the ACC obtained without fluctuating fluxes. These changes exclude (with the aid of experiment $\mathrm{BH}^{*}$ ) the effect of non-zero time-mean fluxes that cannot be completely excluded from the experiments. The MOC changes are related to the change in the meridional density difference between two latitudinal strips in the northern North Atlantic and in the South Atlantic, defined in a way similar to that in Rahmstorf (1996) and Thorpe et al. (2001). The 
ACC changes are related to a reduction in meridional gradient in the depth-integrated density.

These density changes are likely caused by changes in vertical mixing induced by fluctuating surface fluxes. In the MPI-OM model, large changes in the vertical mixing are related to the changes in the convective mixing. Fluctuating fluxes alter convective mixing in a non-linear way. In the mostly unstable regions, e.g. in the GIN Seas and near the Antarctic Peninsula, positive buoyancy anomalies can restrain convective events, whereas negative buoyancy anomalies do not significantly affect the convective behaviour, leading to an overall reduction in the convective mixing. In mostly stable regions, e.g. in the subtropical and mid-latitude oceans, large negative buoyancy anomalies can trigger additional convective events, whereas positive buoyancy anomalies do not significantly change the convective behaviour, leading to an overall strengthening of the convective mixing.

The conclusions about the effect of fluctuating fluxes on the convective mixing are drawn within the framework of a coarse resolution version of the MPI-OM. In another OGCM, which produces a different stratification with a different distribution of convective activity, the effect of fluctuating fluxes on the convective mixing, which is closely related to the mean stratification, can be different. As a consequence, the exact numbers concerning the changes in the MOC and ACC due to the fluctuating fluxes can depend on the model used. Nevertheless, the mechanism through which fluctuating daily fluxes alter the convective mixing should operate in other models, and probably also in nature.

Acknowledgments This study is supported by the German Research Foundation in the Special Research Areas (SFB 512), "Cyclones and the North Atlantic Climate System". We thank Uwe Mikolajewicz and two anonymous reviewers for valuable suggestions in improving this manuscript. Thanks also to Johann Jungclaus who provided us a program to calculate the volume transports between the Nordic Seas and the North Atlantic which helped us to answer a question raised by a reviewer.

\section{References}

Cunningham S, Alderson S, King BA, Brandon MA (2003) Transport and variability of the ACC. J Geophys Res 108. doi: 10.1029/2001JC001147

Frankignoul C, Czaja A, L'Heveder B (1998) Air-sea feedback in the North Atlantic and surface boundary conditions for ocean models. J Clim 11:2310-2324

Gent PR, Willebrand J, McDougall J, McWilliams JC (1995) Parameterising eddy induced tracer transports in ocean circulation models. J Phys Oceanogr 25:463-474

Gregg M, Sanford T, Winkel D (2003) Reduced mixing from the breaking of internal waves in equatorial waters. Nature 422:513515

Griffies SM (1998) The Gent-McWilliams skew flux. J Phys Oceanogr 28:831-841
Haak H, Jungclaus JH, Mikolajewicz U, Latif M (2003) Formation and propagation of great salinity anomalies. Geophys Res Lett 30. doi:10.1029/2003GL017065

Hughes T, Weaver A (1994) Multiple equillibrium of an asymmetric two-basin model. J Phys Oceanogr 24:619-637

Jungclaus JH, Haak H, Latif M, Mikolajewicz U (2005) Arctic-North Atlantic interactions and multidecadal variability of the meridional overturning circulation. J Clim 18:4013-4031

Kuhlbrodt T, Griesel A, Montoya M, Levermann A, Hoffmann M, Rahmstorf S (2007) On the driving processes of the oceanic meridional overturning circulation. Rev Geophys 45. doi: 10.1029/2004RG000166

Kuhlbrodt T, Monahan A (2003) Stochastic stability of open-ocean deep convection. J Phys Oceanogr 33:2764-2780

Ledwell J, Montgomery E, Polzin K, St. Laurent, Schmitt L, Toole J (2000) Evidence for enhanced mixing over rough topography in the abyssal ocean. Nature 403:179-182

Ledwell J, Watson A, Law C (1993) Evidence for slow mixing across the pycnocline from an open-ocean tracer release experiment. Nature 364:701-703

Legutke S, Voss R (1999) The Hamburg atmosphere-ocean coupled circulation model ECHO-G. DKRZ, Tech. Rep. 18, Hamburg, Germany

Marsland SJ, Haak H, Jungclaus JH, Latif M, Roeske F (2003) The Max-Planck-Institute global ocean/sea ice model with orthogonal curvilinear coordinates. Ocean Model 5:91-127

Marti O, Braconnot P, Dufresne J-L, Bellier J, Benshila R, Bony S, Brockmann P, Cadule P, Caubel A, Codron F, de Noblet N, Denvil S, Fairhead L, Fichefet T, Foujols M-A, Friedlingstein P, Goosse H, Grandpeix J-Y, Guilyardi E, Hourdin F, Krinner G, Lévy C, Madec G, Mignot J, Musat I, Swingedouw D, Talandier C (2009) Key features of the IPSL ocean atmosphere model and its sensitivity to atmospheric resolution. Clim Dyn (in press)

Moum J, Caldwell D, Nash J , Gunderson G (2002) Observations of boundary mixing over the continental slope. J Phys Oceanogr 32:2113-2130

Munk W, Wunsch C (1998) Abyssal recipies II. Energetics of tidal and wind mixing. Deep Sea Res I 45:1977-2010

Nowlin WDJ, Klinck JM (1986) The physics of the ACC. Rev Geophys 24:469-491

Pacanowski RC, Philander SGH (1981) Parameterisation of vertical mixing in numerical models of tropical oceans. J Phys Oceanogr 11:1443-1451

Rahmstorf S (1995) Multiple convection patterns and thermohaline flow in an idealized OGCM. J Clim 8:3028-3039

Rahmstorf S, Willebrand J (1995) The role of temperature feedback in stabilizing the thermohaline circulation. J Phys Oceanogr 25:787-805

Rahmstorf S (1996) On the freshwater forcing and transport of the Atlantic thermohaline circulation. Clim Dyn 12:799-811

Raible C, Luksch U, Fraedrich K, Voss R (2001) North Atlantic decadal regimes in a coupled GCM simulation. Clim Dyn 18:321-330

Redi MH (1982) Oceanic isopycnal mixing by coordinate rotation. J Phys Oceanogr 12:1154-1158

Russell JL, Stouffer RJ, Dixon KW (2006) Intercomparison of the southern ocean circulations in IPCC coupled model control simulations. J Clim 19:4560-4575

Sloyan BM (2005) Spatial variability of mixing in the Southern Ocean. Geophys Res Lett 32. doi:10.1029/2005GL023568

Stouffer RJ, Yin J, Gregory JM, Dixon KW, Spelman MJ, Hurlin W, Weaver AJ, Eby M, Flato GM, Hasumi H, Hu A, Jungclaus JH, Kamenkovich IV, Levermann A, Montoya M, Murakami S, Nawrath S, Oka A, Peltier WR, Robitaille DY, Sokolov A, Vettoretti G, Webber SL (2006) Investigating the causes of the response of the thermohaline circulation to past and future climate changes. J Clim 19:1365-1387 
Swingedouw D, Braconnot P, Delecluse P, Guilyardi E, Marti O (2007) Quantifying the AMOC feedbacks during a 2xCO2 stabilization experiment with land-ice melting. Clim Dyn 29:521-534

Thorpe RB, Gregory JM, Johns TC, Wood RA, Mitchell JFB (2001) Mechanisms determining the Atlantic thermohaline circulation response to greenhouse gas forcing in a non-flux adjusted coupled climate model. J Clim 14:3102-3116

Toggweiler JR, Samuels B (1995) Effect of Drake Passage on the global thermohaline circulation. Deep Sea Res 42:477-500

Tziperman E (1986) On the role of interior mixing and air sea fluxes in determining the stratification and circulation of the oceans. J Phys Oceanogr 16:680-693 von Storch J-S (2000) Signatures of air-sea interactions in a coupled atmosphere-ocean GCM. J Clim 13:3361-3379

von Storch J-S, Montavez JP, Beena BS (2005) EMAD: an empirical model of air-sea fluxes. Meteor Zeitschrift 14:755-762

Walin G (1982) On the relation between sea-surface heat flow and thermal circulation in the oceans. Tellus 34:187-195

Webb DJ, Suginohara N (2001) Vertical mixing in the ocean. Nature 409:37 